\section{Pacific Northwest}

National Laboratory

Operated by Battelle for the

U.S. Department of Energy

\title{
FY 2005 Miniature Spherical Retroreflectors Final Report
}

\author{
N. C. Anheier \\ B. E. Bernacki \\ B. R. Johnson \\ B. J. Riley \\ W. A. Sliger
}

December 2005

Prepared for the U.S. Department of Energy under Contract DE-AC05-76RL01830 


\title{
DISCLAIMER
}

This report was prepared as an account of work sponsored by an agency of the United States Government. Neither the United States Government nor any agency thereof, nor Battelle Memorial Institute, nor any of their employees, makes any warranty, express or implied, or assumes any legal liability or responsibility for the accuracy, completeness, or usefulness of any information, apparatus, product, or process disclosed, or represents that its use would not infringe privately owned rights. Reference herein to any specific commercial product, process, or service by trade name, trademark, manufacturer, or otherwise does not necessarily constitute or imply its endorsement, recommendation, or favoring by the United States Government or any agency thereof, or Battelle Memorial Institute. The views and opinions of authors expressed herein do not necessarily state or reflect those of the United States Government or any agency thereof.

\author{
PACIFIC NORTHWEST NATIONAL LABORATORY \\ operated by \\ BATTELLE \\ for the \\ UNITED STATES DEPARTMENT OF ENERGY \\ under Contract DE-AC05-76RL01830
}

Printed in the United States of America
Available to DOE and DOE contractors from the Office of Scientific and Technical Information,
P.O. Box 62, Oak Ridge, TN 37831-0062;
ph: (865) 576-8401
fax: $(865)$ 576-5728
email: reports@adonis.osti.gov

\begin{abstract}
Available to the public from the National Technical Information Service, U.S. Department of Commerce, 5285 Port Royal Rd., Springfield, VA 22161 ph: (800) 553-6847 fax: $(703) 605-6900$ email: orders@ntis.fedworld.gov online ordering: http://www.ntis.gov/ordering.htm
\end{abstract}

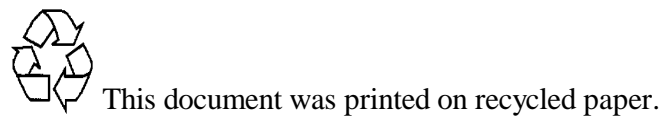




\title{
FY 2005 Miniature Spherical Retroreflectors Final Report
}

\author{
N. C. Anheier \\ B. E. Bernacki \\ B. R. Johnson \\ B. J. Riley \\ W. A. Sliger
}

December 2005

Prepared for

the U.S. Department of Energy

under Contract DE-AC05-76RL01830

Pacific Northwest National Laboratory

Richland, Washington 99352 



\section{Summary}

Research done by the Infrared Photonics team at Pacific Northwest National Laboratory (PNNL) is focused on developing miniature spherical retroreflectors using the unique optical and material properties of chalcogenide glass to reduce both performance limiting spherical and chromatic aberrations. The optimized optical performance will provide efficient signal retroreflection that enables a broad range of remote detection scenarios for mid-wave infrared (MWIR) and long-wave infrared (LWIR) sensing applications. Miniature spherical retroreflectors can be developed to aid in the detection of signatures of nuclear proliferation or other chemical vapor or radiation signatures. Miniature spherical retroreflectors are not only well suited to traditional bistatic LIDAR methods for chemical plume detection and identification, but could enable remote detection of difficult semi-volatile chemical materials or low level radiation sources.

During FY 2005, PNNL's Infrared Photonics research team made significant progress developing spherical retroreflector approaches based on chalcogenide glass. Optical ray trace modeling and stray light simulation analysis were used to scope the optical performance and develop promising optical designs. Viscosity measurements on chalcogenide $\left(\mathrm{As}_{2} \mathrm{~S}_{3}\right)$ glass were performed to study the thermal visco-elastic behavior of thermally elevated glass. A fiber draw tower was modified with a Flow Focusing $@$ micro-nozzle to develop precision miniature sphere fabrication methods. Initial micro-nozzle experiments demonstrated the ability to shear the viscous glass stream into droplets by judicious control of the glass melt temperature and nozzle flow pressures. These favorable results gave evidence that this approach could lead to an optical sphere fabrication method that is amenable to mass-production. 


\section{Contents}

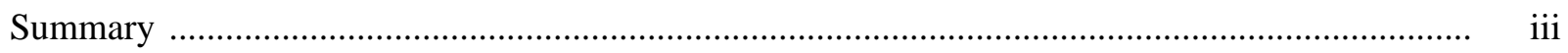

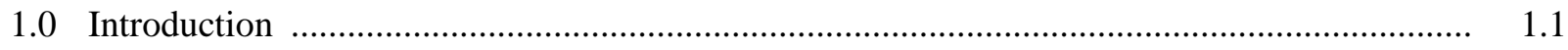

2.0 Retroreflection Optical Design Considerations ........................................................... 2.1

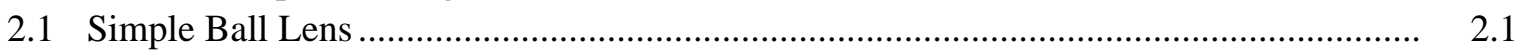

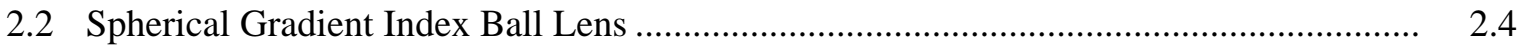

2.3 Piecewise Continuous Step Index Ball Lens .............................................................. 2.7

3.0 Chalcogenide Glass Viscosity Measurements .......................................................... 3.1

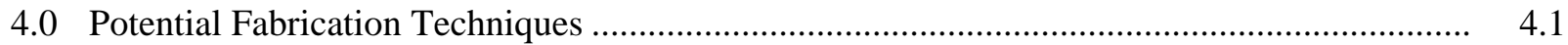

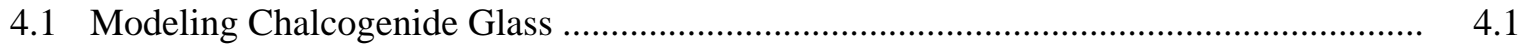

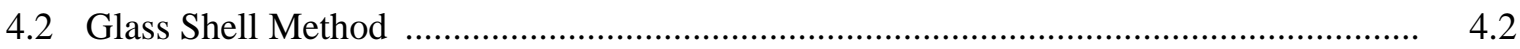

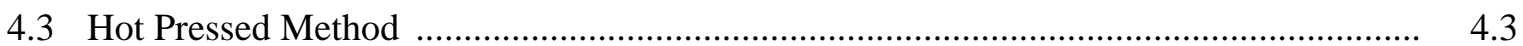

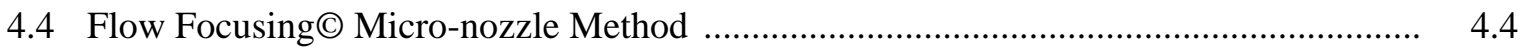

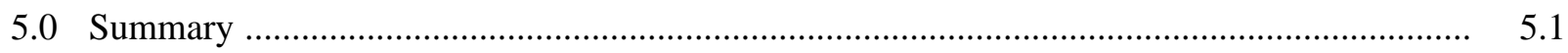

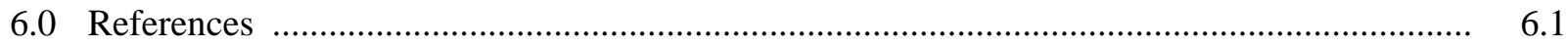




\section{Figures}

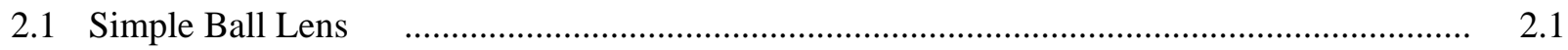

2.2 Index Versus Ray Height Relationship ...................................................................... 2.3

2.3 Spherical Aberration of Simple Ball Lens........................................................................ 2.3

2.4 Non-sequential Ray Trace Analysis of Retroreflector......................................................... 2.4

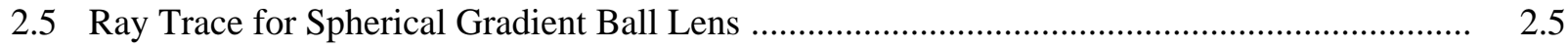

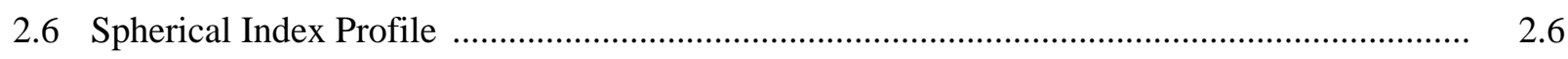

2.7 Spherical Gradient Ball Lens ..................................................................................... 2.6

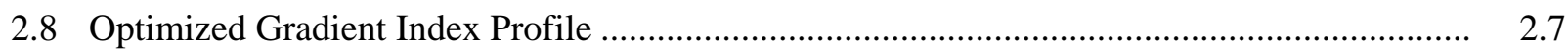

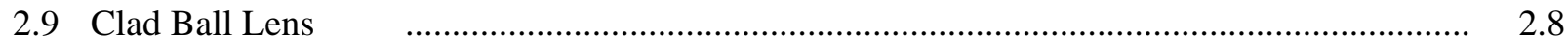

2.10 Optimized Clad Ball Lens Index Profile _.................................................................... 2.8

2.11 Non-sequential Ray Trace Analysis of Clad Ball Lens ....................................................... 2.9

2.12 Uniform and Step Index Retroreflector Performance Comparison ....................................... 2.9

3.1 Chalcogenide Glass Produced at PNNL ………………………………………….... 3.2

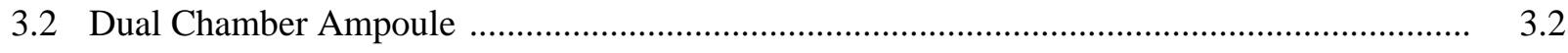

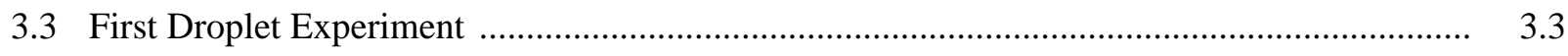

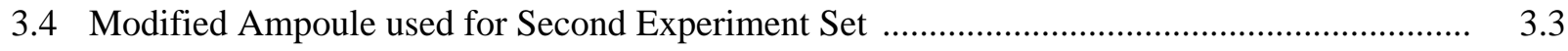

$3.5 \quad$ Second Droplet Experiment …………………………..................................................... $\quad 3.4$

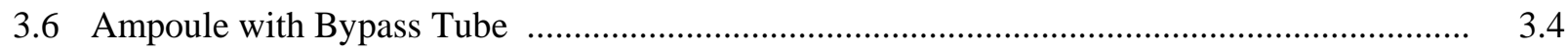

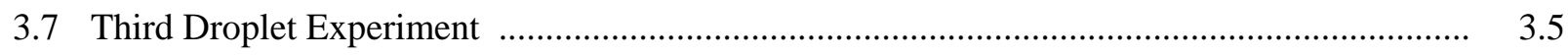

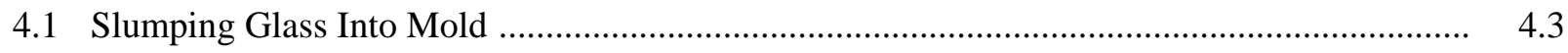

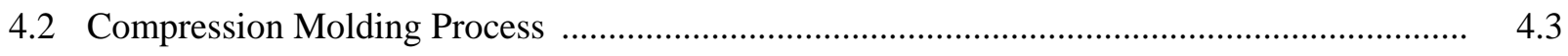


4.3 PNNL Draw Tower with Flow Focusing Assembly

4.4 Flow Focus Process 


\subsection{Introduction}

Remote chemical detection using LIDAR methods have employed corner cube retroreflectors to provide a strong optical return to the laser transceiver. This return is spectrally analyzed to ascertain the properties of the intervening atmosphere. In many scenarios, it is difficult or impossible to position and align a macroscopic retroreflector. It is well known that a glass sphere having a refractive index of 2.0 provides an ideal paraxial retroreflector (in optical systems, a paraxial ray is both close to and nearly parallel to the optical axis, which for these applications is from the center of the collection optic through the center of the retro-sphere). A miniature sphere retroreflector has a number of unique properties that make them attractive for many remote sensing applications. A sphere retroreflector can be deployed without concern of precise placement since the spherical geometry provides an omni-directional return. The ideal sphere diameter is in the range of 1 to $5 \mathrm{~mm}$. They can be easily deployed in large numbers, yet remain indistinguishable from the background environment.

Since the incident laser light is collected and tightly focused by the sphere at the sphere glass-air interface, laser-induce fluorescence methods can be employed to detect the presence of either chemical or radiation sources, at a large standoff distances, by several methods. Two detection strategies include a sphere coated with either a radiation or chemical sensitive fluorescence material (chemical or radiation detection) or with an optically stimulated luminescent material (radiation detection). Since the fluorescence emanates from a point source, the sphere collects and collimates this emission and then directs it back to the laser transceiver.

In late FY2001 DARPA/MTO funded PNNL to initiate development of chalcogenide glass waveguide-based photonics technology for integrating miniature, multi-wavelength QC laser systems at the wafer-scale. Beginning in FY04 NA-22 began co-funding the development of chalcogenide glass optical components for use with QC laser-based chemical sensing systems being developed under PNNL's infrared sensing program. Beginning in FY05 NA-22 also began funding the development of miniature spherical retroreflectors, fabricated by using the unique properties of chalcogenide glass. Chalcogenide glasses are attractive materials for fabricating mid-wave infrared (MWIR) and long-wave infrared (LWIR) photonic components because they combine relatively low transmission losses with a variety of unique optical and material properties.

The bottleneck that limits the miniature retroreflector approach is miniature sphere fabrication methods that produce the appropriate spherical gradient index profile. Any departures from the correct optical prescription will result in large optical losses that greatly diminish the potential of this approach. PNNL's motivation to utilize chalcogenide glass for this application is the potential of solving the fabrication impediment by exploiting this glass's unique combination of optical and material properties. Photomodification of chalcogenide glass have been well documented in a prior NA-22 report (Anheier, et al. 2004). One of the possible transformations is photodarkening, which corresponds to a photo-induced red shift of the absorption spectrum. This shift leads to an increase of the refractive index. The photodarkening effect has the potential to produce the required refractive index profiles. In addition to photodarkening, chalcogenide glasses have material properties that are very similar to the more common low-temperature glasses used in aspheric lens molding. For example, a readily available 
commercial chalcogenide glass, AMTIR3 from Amorphous Materials Inc., has a glass transition temperature of $278^{\circ} \mathrm{C}$, which is very close to that of Corning replica mold glass. The glass transition temperature is approximately the temperature at which glass compression molding takes place.

Therefore, the extension of already existing molding technology to the chalcogenide glasses is relatively straightforward and can be exploited to produce the structures that are likely needed to make efficient retroreflectors for the MWIR and LWIR sensing applications.

In this report we provide a summary of the FY 2005 research progress for the Miniature Spherical Retroreflector project (PL211A). In Section 2, we provide background on optical design approaches for miniature spherical retroreflectors. In Section 3 we discuss the visco-elastic measurements of thermally elevated chalcogenide and in Section 4, we summarize potential sphere fabrication approaches using chalcogenide glass. 


\subsection{Retroreflector Optical Design Considerations}

Many types of optical arrangements are possible to reflect a collimated beam back towards its origin along its original optical axis. In this application we desire a completely isotropic structure, which eliminates all-reflective solutions (corner cubes and prisms). What we seek is a structure that reflects a beam without regard to the orientation of the device, and the most obvious choice for form is that of a spherical reflector or ball lens. In this overview we examine the progression of improvements we may practically bring to a ball lens structure to improve directionality and efficiency with respect to the quality of the return beam.

\subsection{Simple Ball Lens}

In its simplest form, the type of retro-reflector that we seek is the simple ball lens. The ball lens has two variables that we can control: its index and radius of curvature. To obtain the smallest possible spot size at the image plane (rear surface of the ball lens) one must optimize the lens using these two variables. Suppose we have a homogeneous ball lens of index $n$, immersed in air, having radius of curvature $R$ as shown in Figure 2.1.

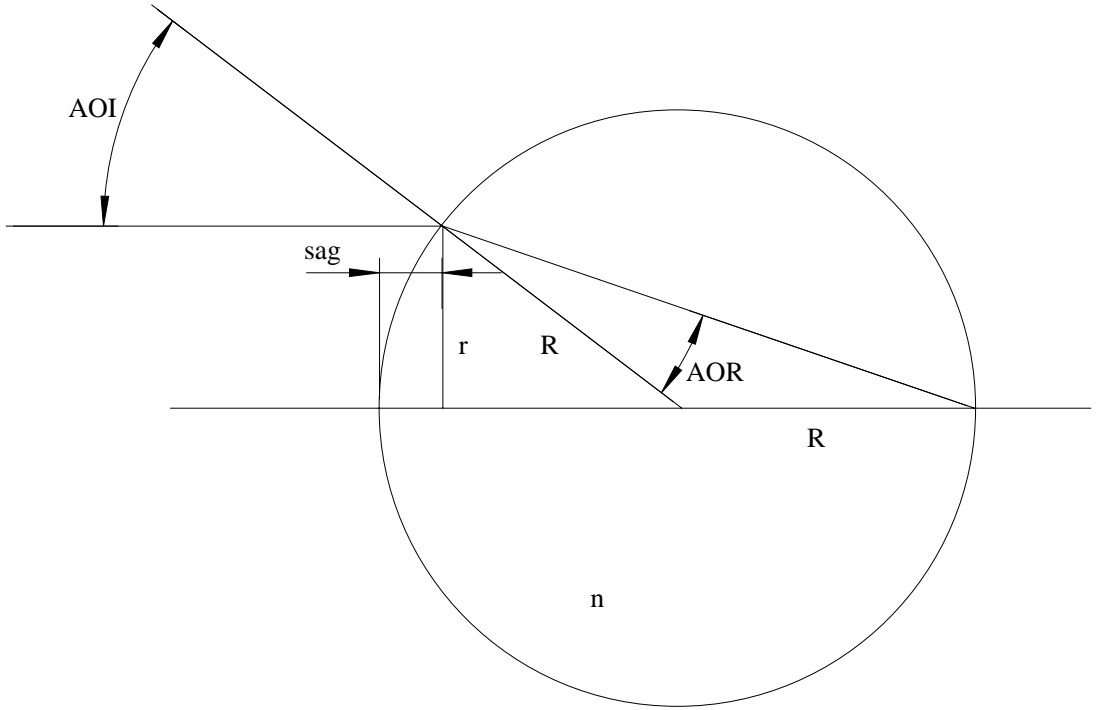

Figure 2.1. A ball lens with ray geometry that brings light to a focus at its rear surface. 
A collimated pencil of light from infinity strikes the ball at an initial angle of incidence (AOI) at height $r$ above the optical axis where it is refracted at some angle of refraction (AOR) according to Snell's Law. If we write an expression for imaging the impinging light at the focal plane we can develop a relationship between the index of refraction $n$, the radius of curvature (and ball radius) $R$, and incoming ray height $r$ as follows:

$$
\begin{aligned}
\sin \left(\theta_{i}\right) & =n \sin \left(\theta_{r}\right) \\
\sin \left(\theta_{i}\right) & =\frac{r}{R} \\
\sin \left(\theta_{r}\right) & =\frac{r}{\sqrt{r^{2}+(2 R-\operatorname{sag})^{2}}} \Rightarrow \operatorname{sag}=R-\sqrt{R^{2}-r^{2}} \\
\sin \left(\theta_{r}\right) & =\frac{r}{\sqrt{r^{2}+\left(R+\sqrt{R^{2}-r^{2}}\right)^{2}}} \\
n & =\frac{\frac{r}{r}}{\sqrt{r^{2}+R^{2}+2 R \sqrt{R^{2}}-r^{2}}+R^{2}-r^{2}} \\
n & =\frac{\sqrt{2 R^{2}+2 R \sqrt{R^{2}-r^{2}}}}{R} \\
n & =\sqrt{\frac{R\left(1+\sqrt{1-\left(\frac{r}{R}\right)^{2}}\right)}{\sqrt{(1+)^{2}}}}
\end{aligned}
$$

So, we can see that as the ray height $r$ increases, the optical index must decrease so that all rays can be brought to a common focus at the image plane with perfect imaging. Furthermore, for a homogeneous glass ball lens, only a restricted pencil of rays will exhibit acceptable performance (depending on our definition of acceptable performance) due to the variation required in index with incoming ray height. For perfect imaging, we see from Figure 2.2 that on-axis rays must see an index of 2, while marginal rays (rays entering the system at the outermost edge of the element) must see an index of $\sqrt{ } 2$ due to the larger degree of refraction at the periphery of the ball lens. 


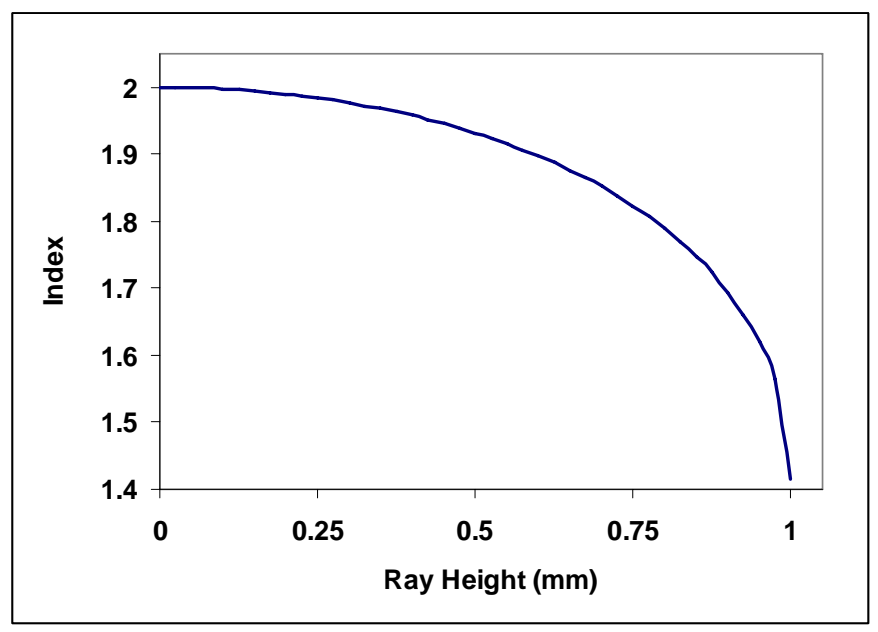

Figure 2.2. Index versus ray height for a ball lens of glass with homogeneous index of refraction $n$ for a ball lens with radius $R$ of $1 \mathrm{~mm}$.

Unfortunately, long-wavelength IR (LWIR) materials typically have an index of refraction exceeding 2 so the simple homogeneous ball lens solution will have poor performance for LWIR $(8 \mu \mathrm{m}$ to $12 \mu \mathrm{m}$ wavelengths) applications. For example, suppose we make a $1 \mathrm{~mm}$ diameter ball lens constructed from $\mathrm{As}_{40} \mathrm{Se}_{60}$ as shown in Figure 2.3. Due to the high index of the glass $(\mathrm{n}=2.77$ at $10 \mu \mathrm{m})$ there is no solution to the equation shown above for perfect imaging in a homogeneous glass ball lens, hence the efficiency of retro-reflection will be low.

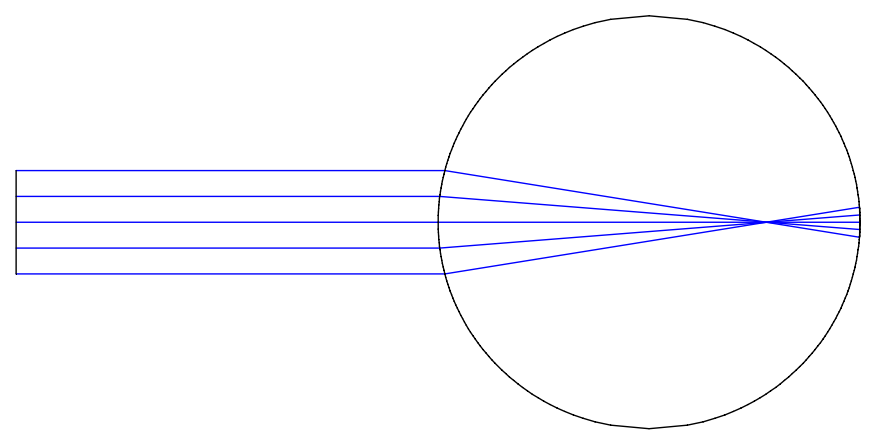

Figure 2.3. A ray trace for a $1 \mathrm{~mm}$ diameter ball lens fabricated from $\mathrm{As}_{40} \mathrm{Se}_{60}$ for use at a wavelength of $10 \mu \mathrm{m}$. Note the severe spherical aberration for the relatively small $(0.25 \mathrm{~mm})$ beam diameter.

The non-sequential ray trace in Figure 2.4 shows the light returned from a $0.25 \mathrm{~mm}$ diameter incident beam into a hemispherical detector centered on the $1 \mathrm{~mm}$ diameter ball lens. For this example, the lens was simulated as having an AR coating with $1 \%$ reflectance, which minimizes first surface return from the high index ball lens. The source is placed $1 \mathrm{~mm}$ in front of the ball and has a $0.25 \mathrm{~mm}$ extent, and the detector is placed $10 \mathrm{~mm}$ back from the ball's front vertex along the optical axis of the source. 


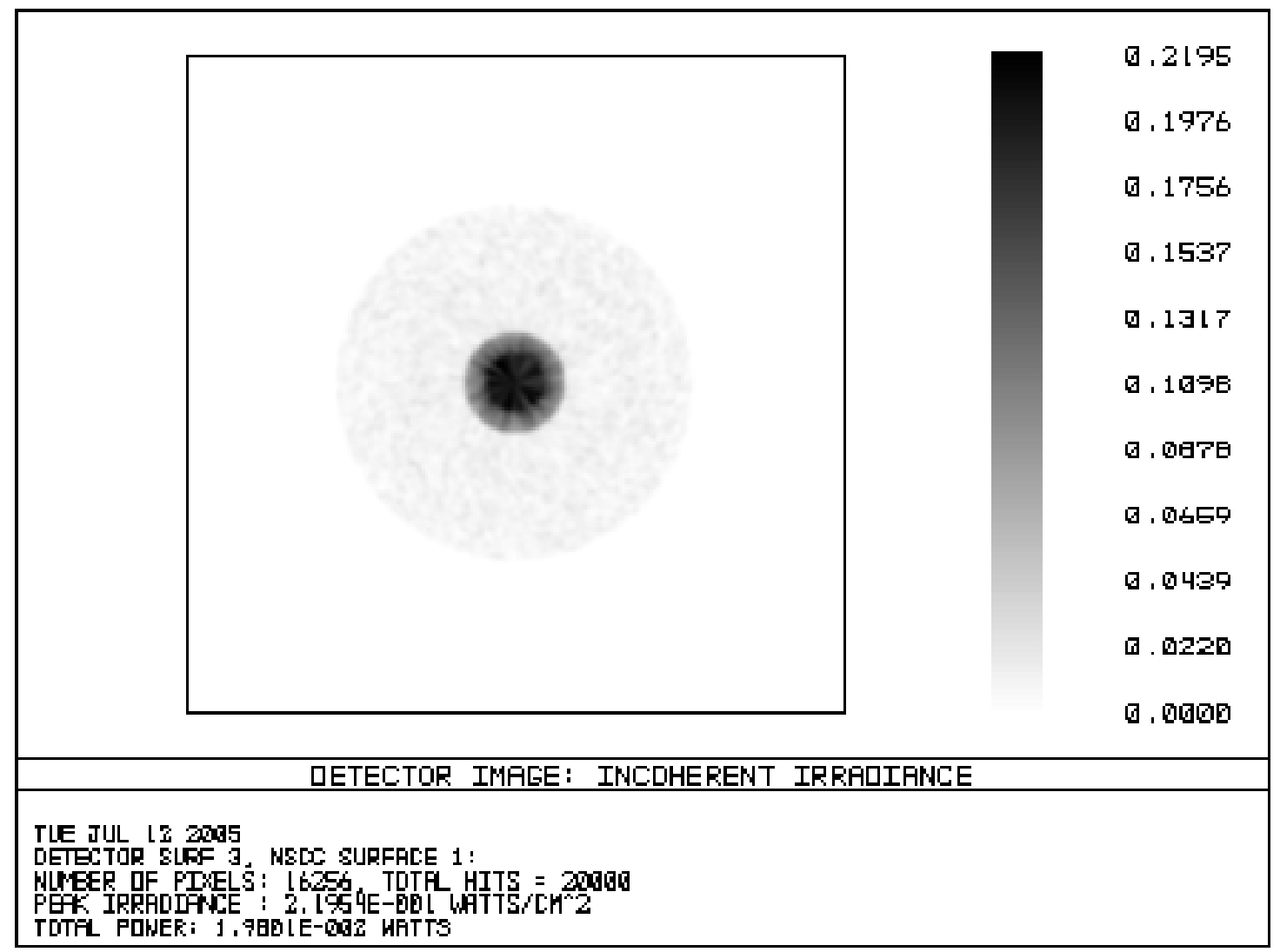

Figure 2.4. Detector image from non-sequential ray trace for the $\mathrm{As}_{40} \mathrm{Se}_{60}$ ball lens having a $1 \mathrm{~mm}$ diameter. The detector is $20 \mathrm{~mm}$ in diameter placed $10 \mathrm{~mm}$ to the rear of the ball lens vertex. Note the halo surrounding the central core, which is itself larger than the $0.25 \mathrm{~mm}$ illumination beam.

\subsection{Spherical Gradient Index Ball Lens}

It was shown by Luneburg (Welford and Winston 1978) that a lens having the following spherical gradient index profile will perfectly image a pencil of collimated rays at its rear surface:

$$
n(r)=\sqrt{2-\left(\frac{r}{a}\right)^{2}}
$$


where $r$ is the distance from the center of the sphere, and $a$ is the sphere's radius. What is immediately evident is that the index at the edge of the sphere must be unity (when $r=a$ ), which is impractical for realizable optical applications (although this index profile can be realized in the microwave region). However, we can greatly improve upon the homogeneous case and approach the performance of a Luneburg lens by finding a gradient index profile having the starting index of unmodified $\mathrm{As}_{40} \mathrm{Se}_{60}$ and then allowing its index to vary with spherical symmetry according the following gradient index profile defined in Zemax lens design code:

$$
\begin{aligned}
& n=n_{0}+\alpha(r-R)+\beta(r-R)^{2} \\
& r=\frac{R}{|R|} \sqrt{x^{2}+y^{2}+(R-z)^{2}}
\end{aligned}
$$

where $R$ is the radius of the ball lens, $z$ is the distance measured from the vertex of the lens, $x$ and $y$ are the usual pupil coordinates in the vertex plane that is tangent to the ball lens, and $n_{o}$ is the index of the glass at the ball's surface. A ray trace of the resulting lens is shown in Figure 2.5 and the optimized index profile is shown in Figure .

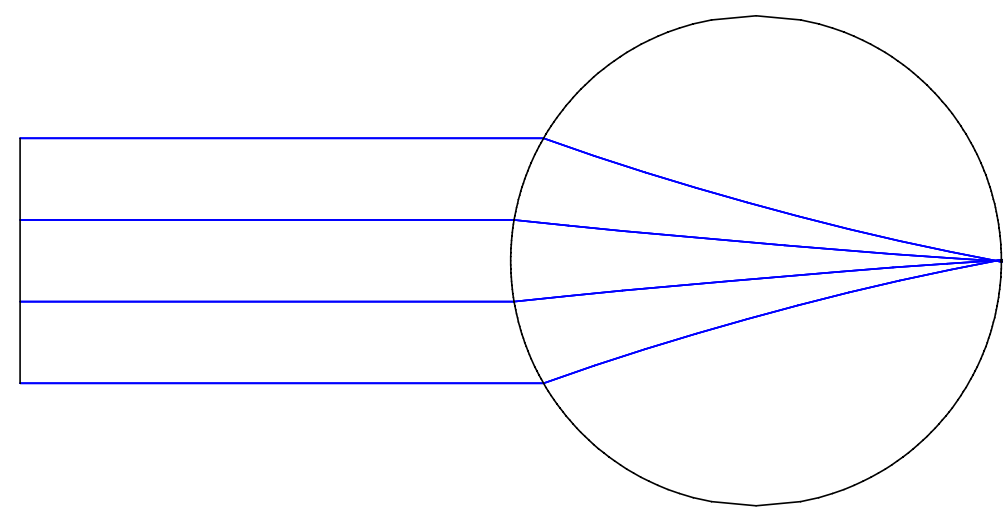

Figure 2.5. Ray trace for the $1 \mathrm{~mm}$ diameter spherical gradient lens having a $0.5 \mathrm{~mm}$ diameter input beam. 


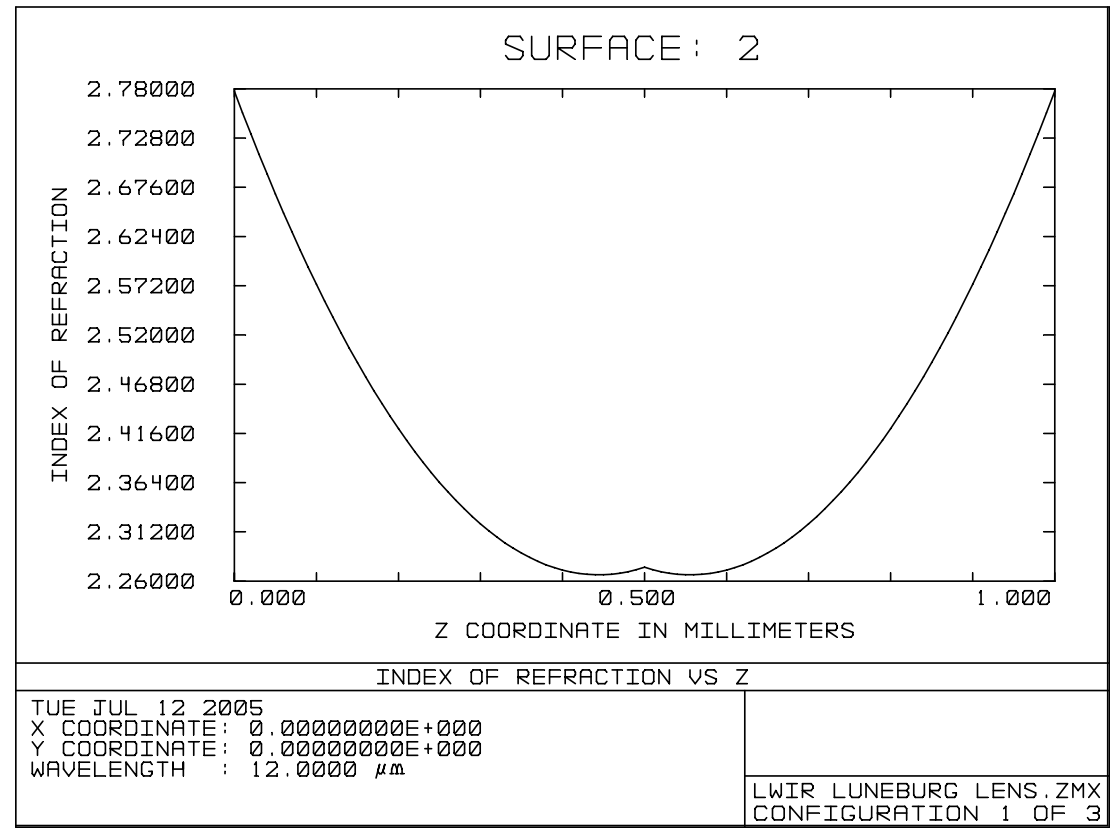

Figure 2.6. Index profile for the spherical gradient index lens.

Note that an approximate change in index of 0.5 is necessary to achieve this optimum profile. While the chalcogenide glass refractive index can be modified through photoinduced processes, a $\Delta \mathrm{n}$ of 0.5 is not realizable in the LWIR region, but rather an order of magnitude less at approximately 0.05 . If we limit our change in index to this value and allow the vertex index to also vary for optimum results, the ray trace of the resulting lens is shown in Figure .

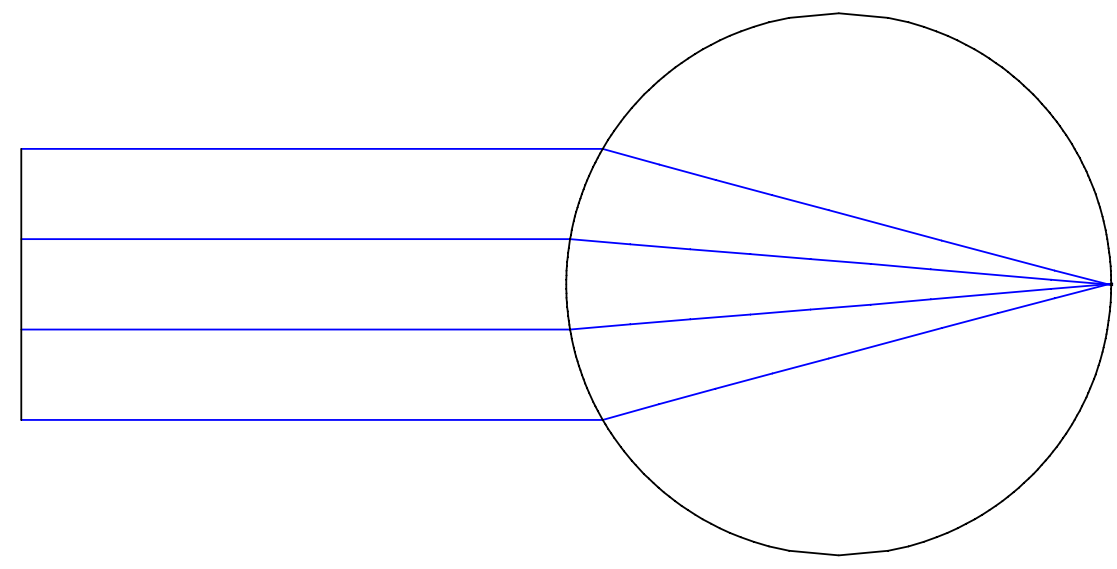

Figure 2.7. Ray drawing showing a $1 \mathrm{~mm}$ diameter $\mathrm{Ax}_{40} \mathrm{Se}_{60}$ ball lens having a spherical gradient index profile with a maximum change in index of 0.05 . The input beam diameter is $0.5 \mathrm{~mm}$. 
The index profile for the above lens is shown below in the Figure. Note that when the value of the index at the surface of the ball is allowed to vary, it finds its optimum value at approximately 2.0 , which agrees with our earlier results for a homogenous glass ball lens. This gradient index approach has been investigated in the visible portion of the electromagnetic spectrum using polymer materials (Koike et al. 1986; Koike et al 1994).

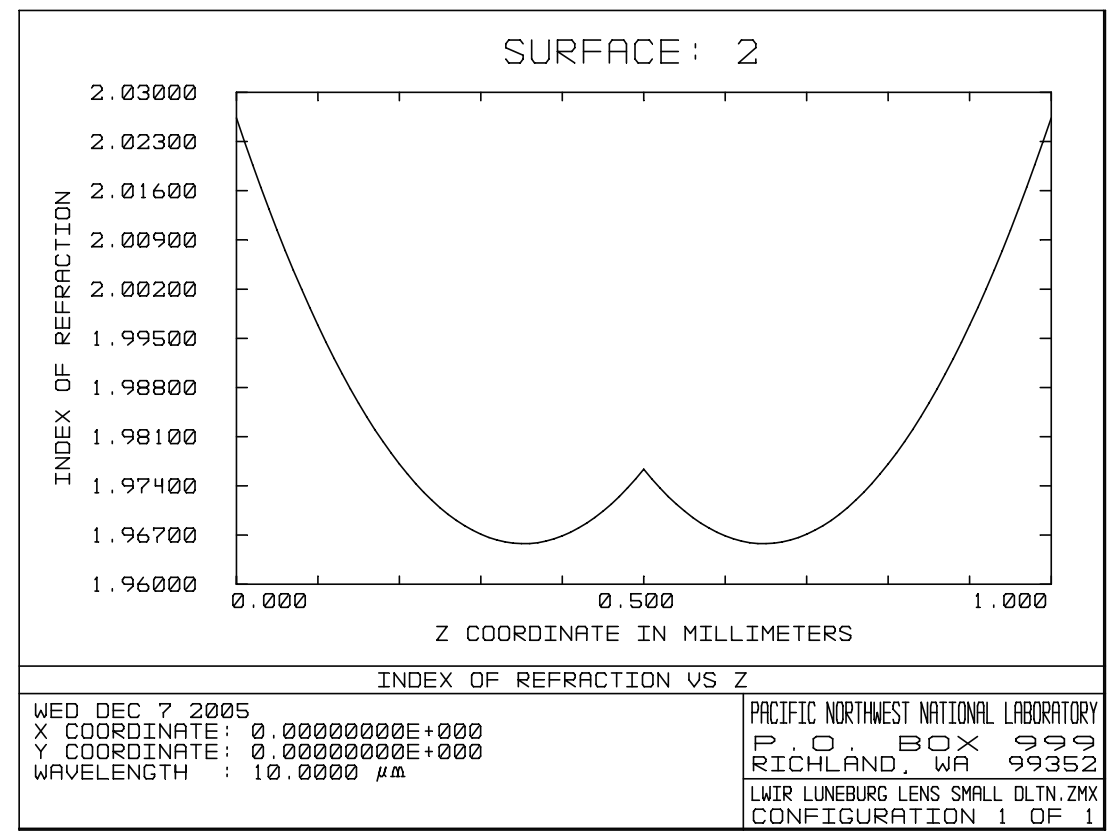

Figure 2.8. Optimum gradient index profile found by optimization when the change in optical index is limited to 0.05 .

\subsection{Piecewise Continuous Step Index Ball Lens}

At this point, two results are clear: 1) the optimum gradient index profile that permits the largest input aperture for a retro-reflecting ball lens is not physically realizable due to the large $\Delta$ n needed for real IR materials, and 2) a physically-realizable gradient index profile cannot provide a solution for a large aperture retro-reflecting ball lens due to the relatively low starting index required (approximately 2). In practice, one would likely overfill a retro-reflector to ensure a high probability of obtaining a return signal. A poorly corrected spherical ball lens-type retro-reflector will result in significant loss at the receiver. One possible approach to this dilemma is to approximate a continuous gradient index with a step index (Kikuchi et al. 1981; Solomin and Alexopoulos 1979).

Beginning with the simplest variant, we will investigate the design and performance of a two-layer ball lens in which a lower index core is clad with a higher index layer, which approximates the continuous gradient solution found earlier. In Figure 2.9 one sees that the outer layer is $\mathrm{As}_{40} \mathrm{Se}_{60}$ (the starting index for the optimized spherical gradient) but that the inner core could vary in index from 2.26 to that of the outer core. At present, the best candidate of available LWIR materials for the core seems to be $\mathrm{ZnS}$, which has an index of about 2.20 at a wavelength of $10 \mu \mathrm{m}$. To keep the comparison on an equal footing with previous examples, we limit the outer radius to $0.5 \mathrm{~mm}$, but allow the thickness of this skin to vary 
to obtain the minimum spot size at the image plane for a $0.5 \mathrm{~mm}$ input beam diameter as shown in Figure . Its index profile is shown below in Figure 2.10 plotted along with the smooth gradient found by optimization in Figure 6.

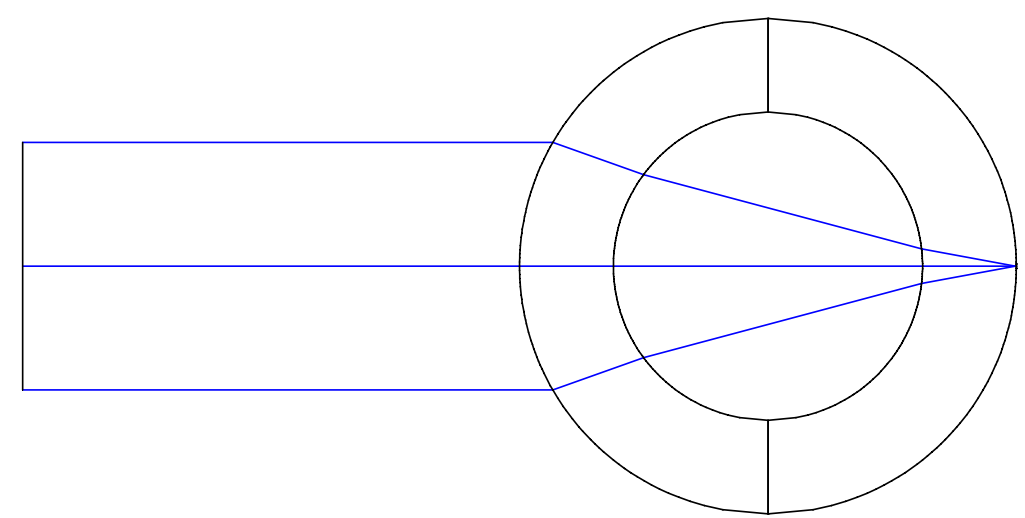

Figure 2.9. A clad ball lens having a $\mathrm{ZnS}$ core and $\mathrm{As}_{40} \mathrm{Se}_{60}$ outer shell.

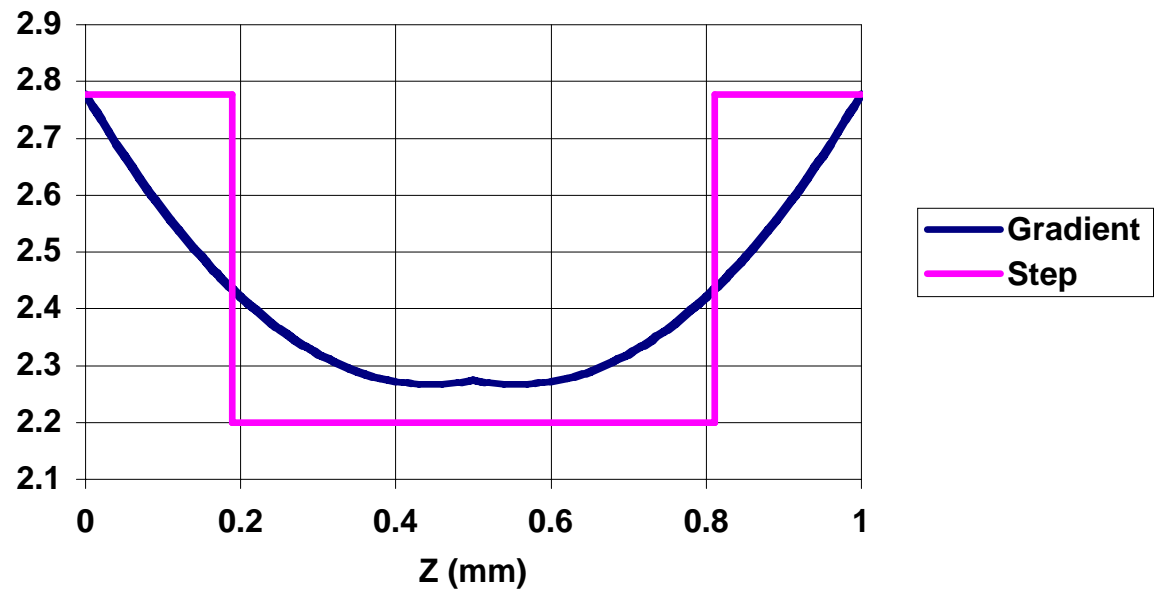

Figure 2.10. Plot of index versus axial coordinate (local $\mathrm{Z}$ axis) for the step index retro-reflector spherical lens along with the optimized gradient profile shown earlier in Figure 2.6.

As was done for the homogeneous glass spherical lens example, a non-sequential model was constructed and illuminated with a $0.5 \mathrm{~mm}$ diameter collimated beam while monitoring the light reflected from the ball $10 \mathrm{~mm}$ from its vertex. The results are shown in Figure 2.11. Both Figure 2.11 and Figure 2.4 are drawn to the same scale and one can readily see that the retro-reflected beam from the step index ball lens is more tightly collimated with a greatly reduced scattered light contribution (halo around the dark central core) due to multiple surface reflections. A plot of the slice through the center of the beam for the two configurations is shown in Figure 2.12 for a side-by-side comparison. 


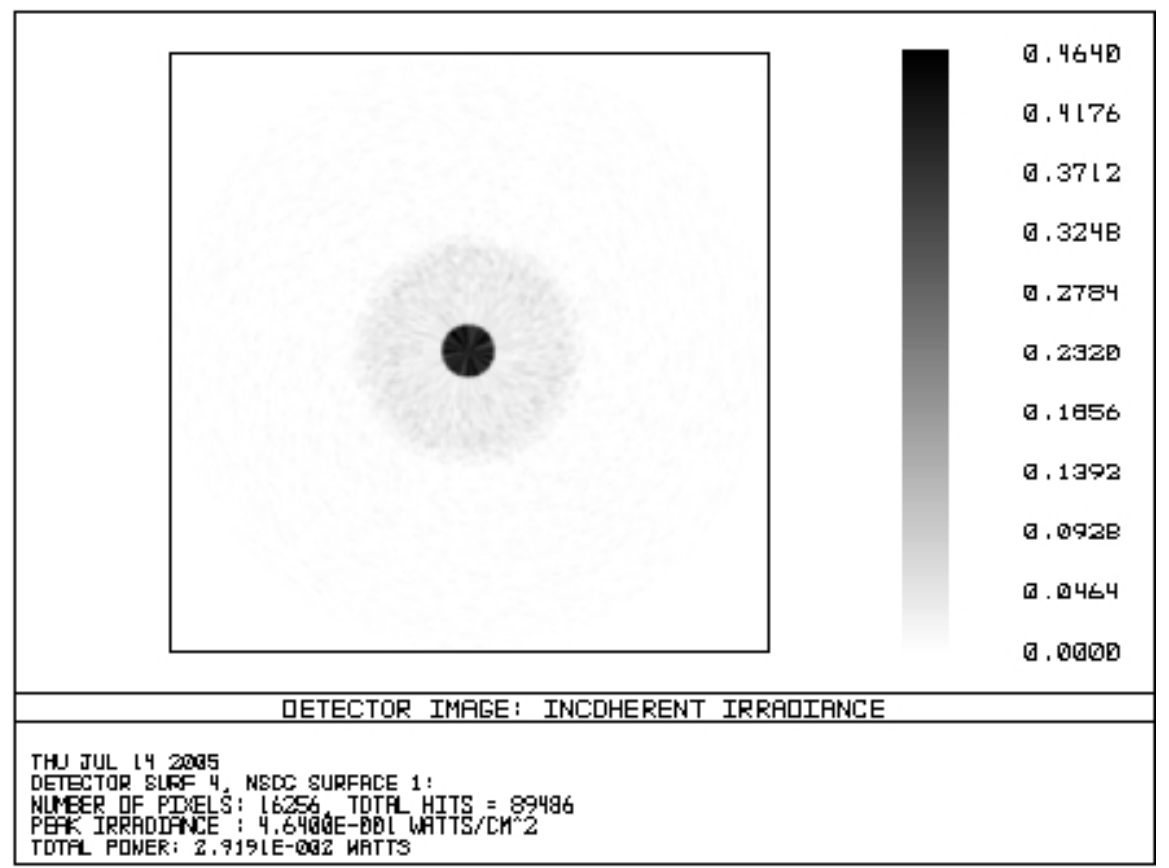

Figure 2.11. Detector view showing the distribution of light returned from the clad spherical lens.

Note the more intense central core of light surrounded by a smaller halo than was found in the homogenous ball lens example.

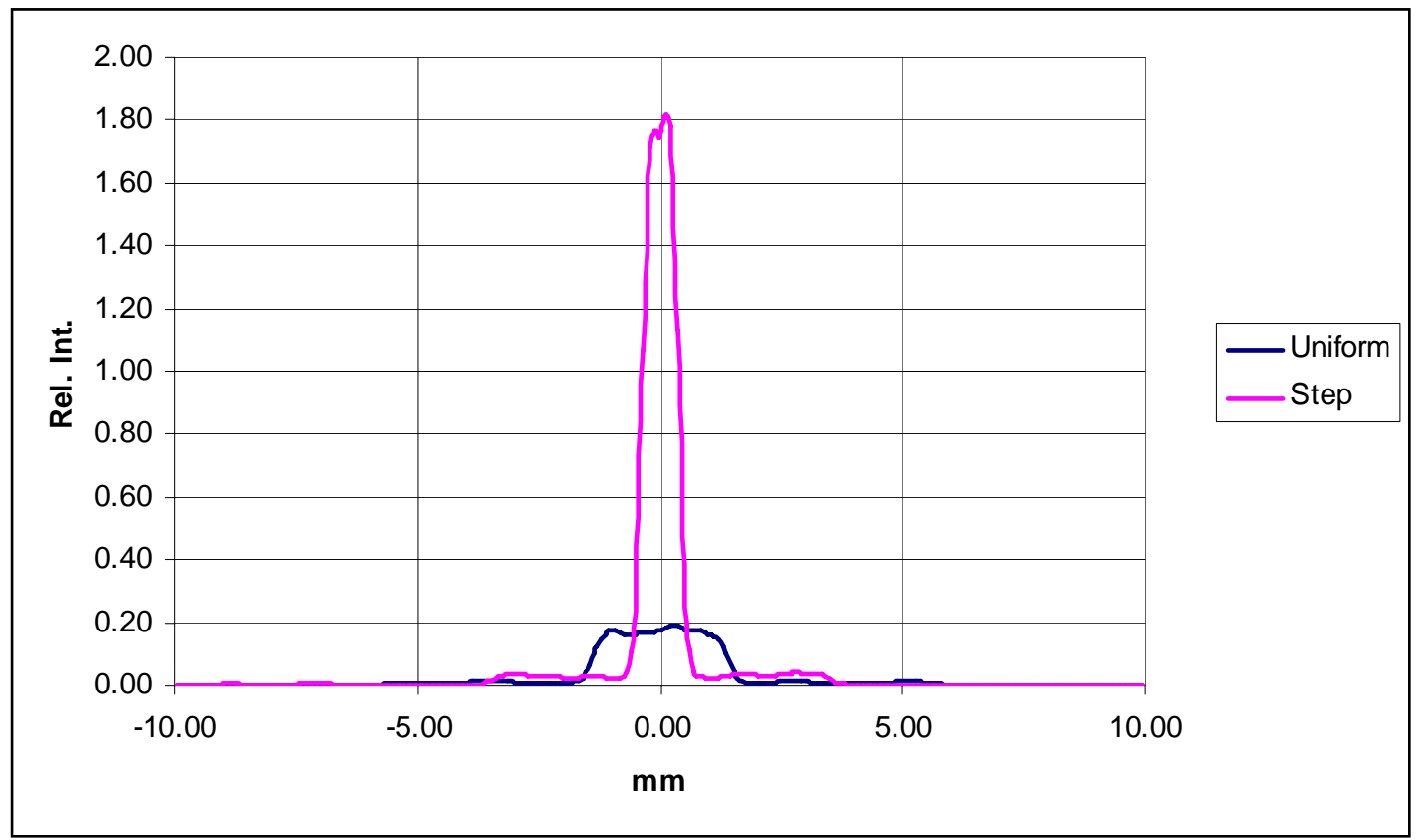

Figure 2.12. The intensity cross-section for the retroreflected beam from the uniform index ball compared with the step index ball lens. 



\subsection{Chalcogenide Glass Viscosity Measurements}

The primary objective of this project was to develop 1 to $5 \mathrm{~mm}$ diameter sphere fabrication methods. The material chosen for this application was arsenic trisulfide $\left(\mathrm{As}_{2} \mathrm{~S}_{3}\right)$, which belongs to the chalcogenide (e.g. containing $\mathrm{S}, \mathrm{Se}$, or $\mathrm{Te}$ ) family of glasses. Before proceeding directly to any fabrication experiments, some basic chalcogenide glass material properties must be established. These measurements are discussed in this section of the report. Potential fabrication approaches include compression molding and draw tower methods. The initial fabrication approach investigated used a fiber draw tower modified with a Flow Focusing Inc. micro-nozzle. Under proper control, the micro-nozzle ejects a steady stream of glass droplets. Surface tension forces pull the molten droplet into a sphere as it falls from the nozzle. The details of the Flow Focusing Inc. micro-nozzle and compression molding are discussed later in this report.

In order for this process to work successfully, two important material properties needed to be determined: 1) the minimum temperature at which molten $\mathrm{As}_{2} \mathrm{~S}_{3}$ would form droplets at the nozzle, and 2) the rate at which the molten droplet would cool and solidify hard enough to prevent deformation upon landing in the collection container. In terms of the fabrication process, the required glass crucible temperature was needed to obtain a glass viscosity just low enough to allow the micro-nozzle to form droplets rather than a glass filament. The cooling rate information was also needed in order to determine the drop height needed to allow droplet solidification.

Figure 3.1 shows approximately $250 \mathrm{~g}$ of $\mathrm{As}_{2} \mathrm{~S}_{3}$ that was batched, melted, and annealed at PNNL's Non-Oxide Materials Synthesis Laboratory. Prior to beginning experiments with the draw tower and micro-nozzle, measurements were performed to determine the minimum temperature at which $\mathrm{As}_{2} \mathrm{~S}_{3}$ would form droplets as it moved through a restriction aperture within a fused quartz ampoule. This approach was chosen to prevent any release of toxic vapors to the atmosphere and it also allowed the convenience of repeated experiments by inverting the ampoule and reheating the glass. Three separate experiments were conducted to determine the droplet-forming temperature. For each experiment, the elapsed time was monitored and the temperature at the restriction was monitored via a portable temperature monitor. 


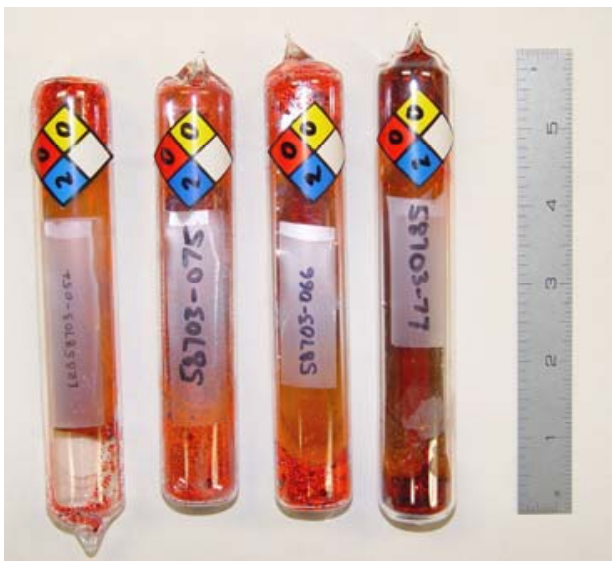

Figure 3.1. $\mathrm{As}_{2} \mathrm{~S}_{3}$ glass produced at PNNL's Non-Oxide Materials Synthesis

Laboratory.

Initially, the straight $20 \mathrm{~cm}$ long quartz ampoule, as seen in Figure 3.2, was used for the droplet testing. A reduced diameter restriction divided the ampoule into two chambers. The restriction diameter was sized to approximate the micro-nozzle diameter used in the subsequent fabrication experiments (Section 4.4). One chamber was loaded with approximately $10 \mathrm{~g}$ of $\mathrm{As}_{2} \mathrm{~S}_{3}$ glass, then evacuated and sealed. The ampoule was instrumented with thermocouples then placed in a secondary containment tube. This entire assembly was inserted into a bottom-loading furnace, with the $\mathrm{As}_{2} \mathrm{~S}_{3}$ glass chamber in the hot zone and the empty chamber protruding below.

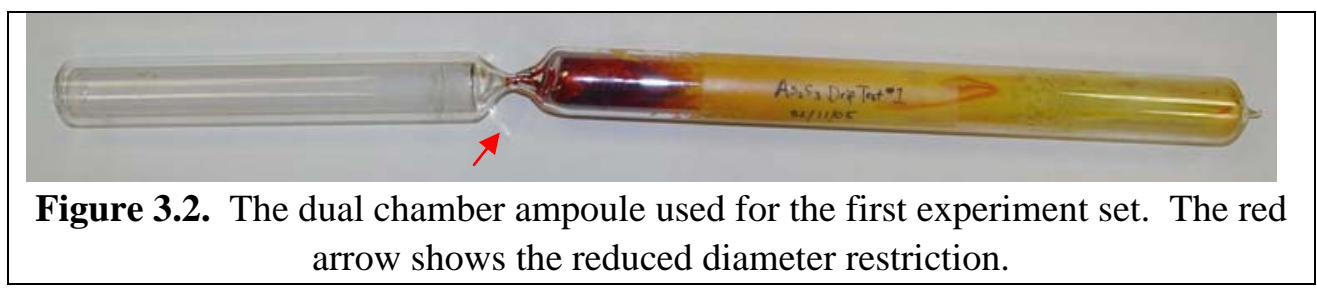

The bottom loading Deltech furnace was pre-heated to $650^{\circ} \mathrm{C}$. Once the furnace reached the desired temperature, the ampoule was inserted into the furnace to begin heating the $\mathrm{As}_{2} \mathrm{~S}_{3}$. The $\mathrm{As}_{2} \mathrm{~S}_{3}$ began subliming at $\sim 250^{\circ} \mathrm{C}$ and continued to do so until $\sim 430^{\circ} \mathrm{C}$ as seen in Figure $3.3 \mathrm{~A}$ as the ampoule restriction plugged up with liquid $\mathrm{As}_{2} \mathrm{~S}_{3}$. Then, at $433^{\circ} \mathrm{C}$, the restriction plug instantly shot into the empty ampoule chamber (see red arrow in Figure 3.3B). This resulted in rapid glass sublimation from the upper ampoule chamber that coated the entire interior of the empty ampoule chamber as shown in Figure 3.3C. By $449^{\circ} \mathrm{C}$, the entire contents of the upper ampoule chamber were evacuated into the lower chamber which all took place in under 6 seconds. 


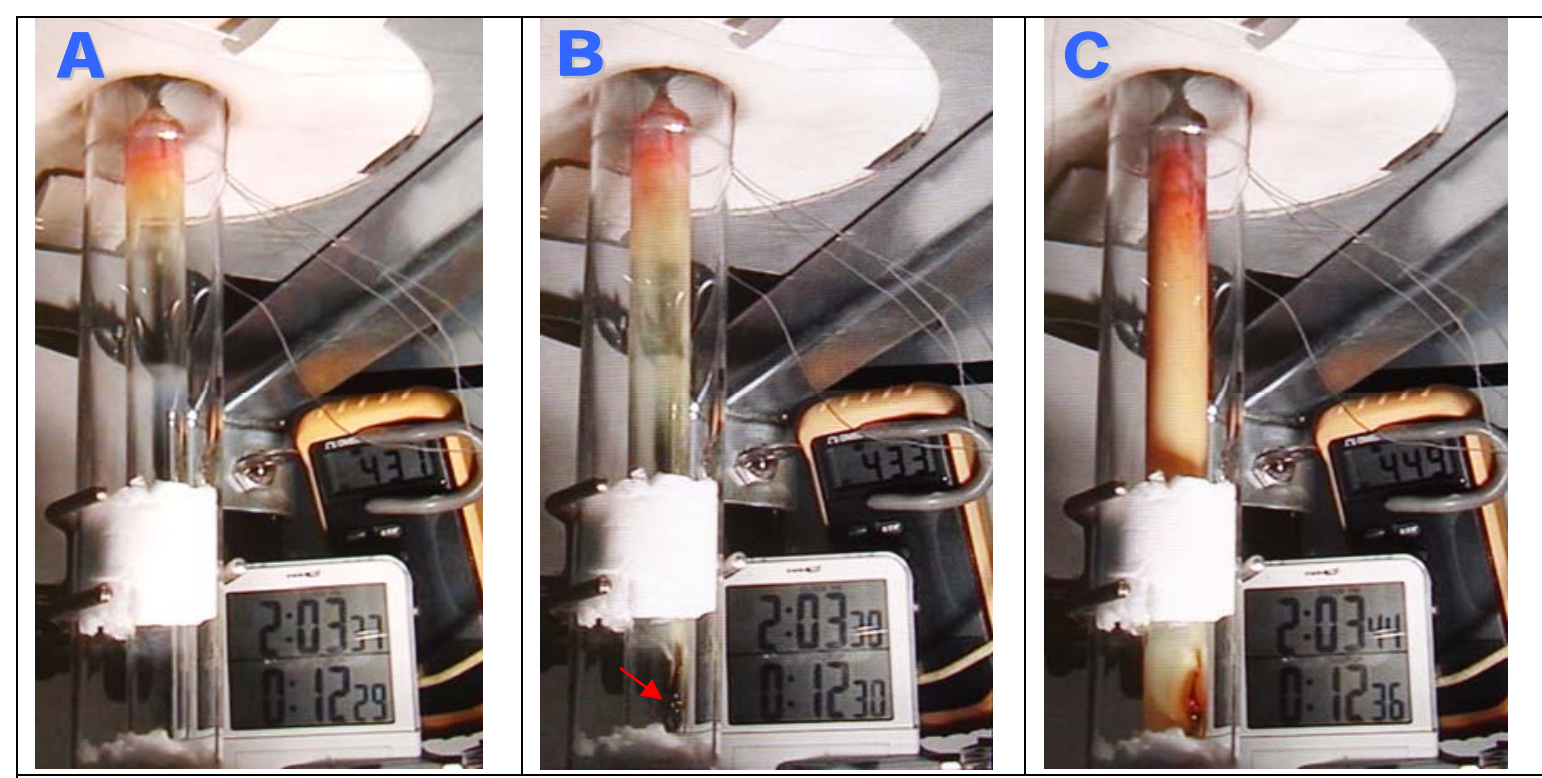

Figure 3.3. Time lapsed collage of first droplet experiment. The red arrow shows the released restriction glass plug.

The main downfall to using this experimental setup was that the ampoule was a sealed system that did not accurately represent the draw tower configuration, since the flow through the restriction was not only limited by the diameter, but also the pressure differential between the top and bottom chambers of the ampoule. Pressure in the lower chamber increased due to the vaporization of the arsenic trisulfide during heating. Since only the top ampoule chamber was being heated, as soon as the heated glass plugged the nozzle, a large pressure gradient was established causing a large driving force to evacuate the hot chamber instead of producing the desired glass droplet formation.

For the second droplet experiment, a different approach was taken. Instead of inserting the ampoule in the furnace after it had reached the temperature set point, the entire ampoule was heated in the furnace so the entire ampoule could come close to pressure equilibrium. This time, the ampoule was much shorter and had a mass of roughly $8 \mathrm{~g} \mathrm{As}_{2} \mathrm{~S}_{3}$ as shown in Figure 3.4.

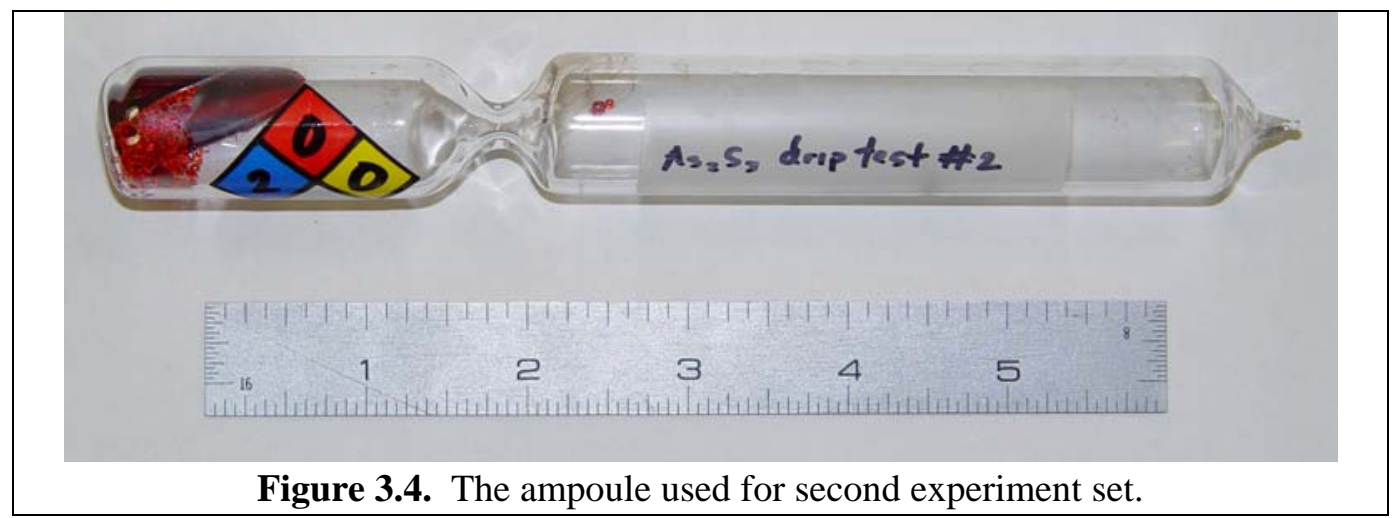


As soon as the ampoule reached $\sim 600^{\circ} \mathrm{C}$, it was removed from the furnace and vertically mounted (Figure 3.5A). Immediately, the glass began to stream from the upper chamber into the chamber region (Figure 3.5C). Droplet formation was observed during this experiment (Figure 3.5B). Distinct droplets proceeded to form between $560^{\circ} \mathrm{C}$ to $450^{\circ} \mathrm{C}$.

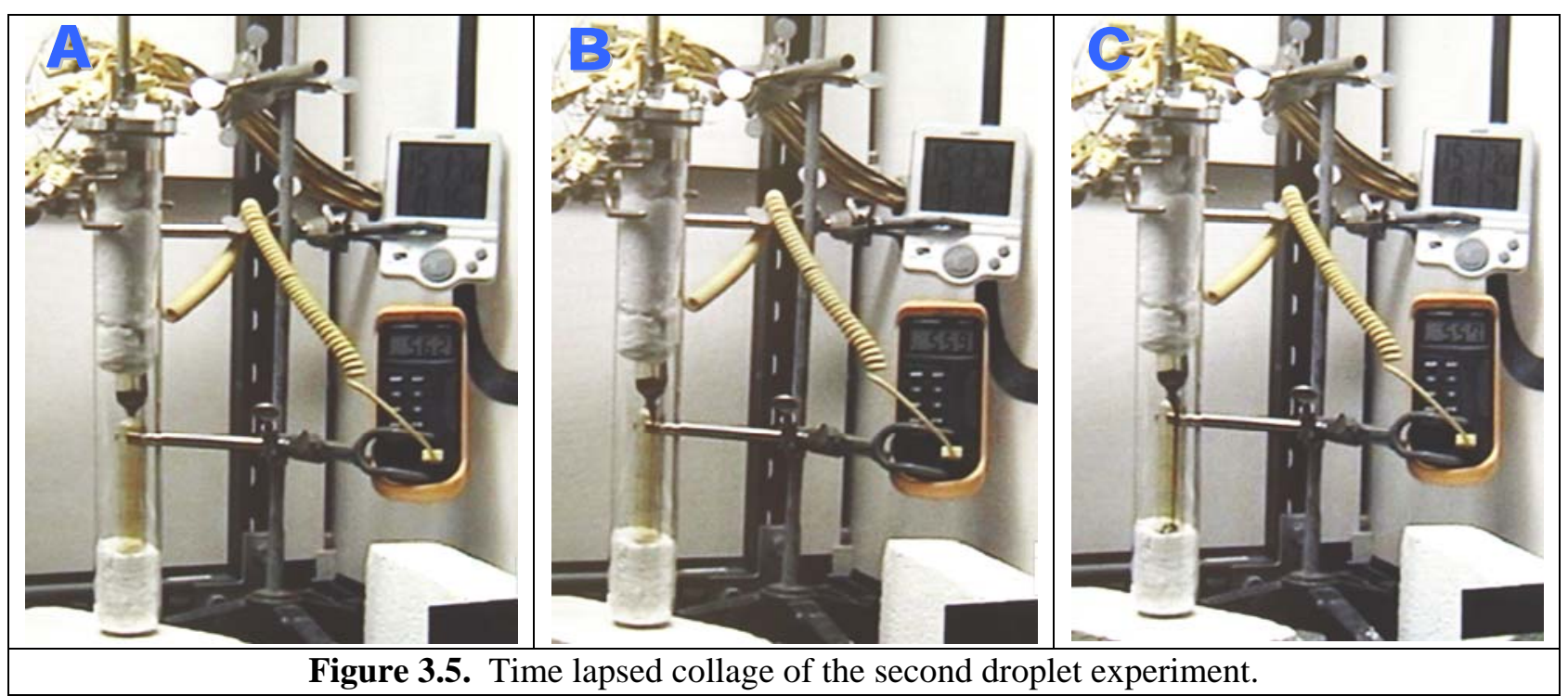

Even with the new ampoule configuration and heating procedure, a significant pressure gradient remained between the top and bottom ampoule chamber. During the process of glass flow, a drastic decrease in pressure occurred in the upper ampoule chamber as it cooled, due to the change in volume of gaseous $\mathrm{As}_{2} \mathrm{~S}_{3}$. This process was manifested during the experiment by droplet formation that would periodically stop then the liquid above the restriction would start to bubble again. The extra release of vapor then equilibrated the pressure, and more glass would then flow from the top to the bottom chamber.

The third experiment set was performed to further minimize any pressure differential between the top and bottom chambers. The ampoule was modified to include a pressure equalization path between the upper and lower chambers as seen in Figure 3.6A \& B.

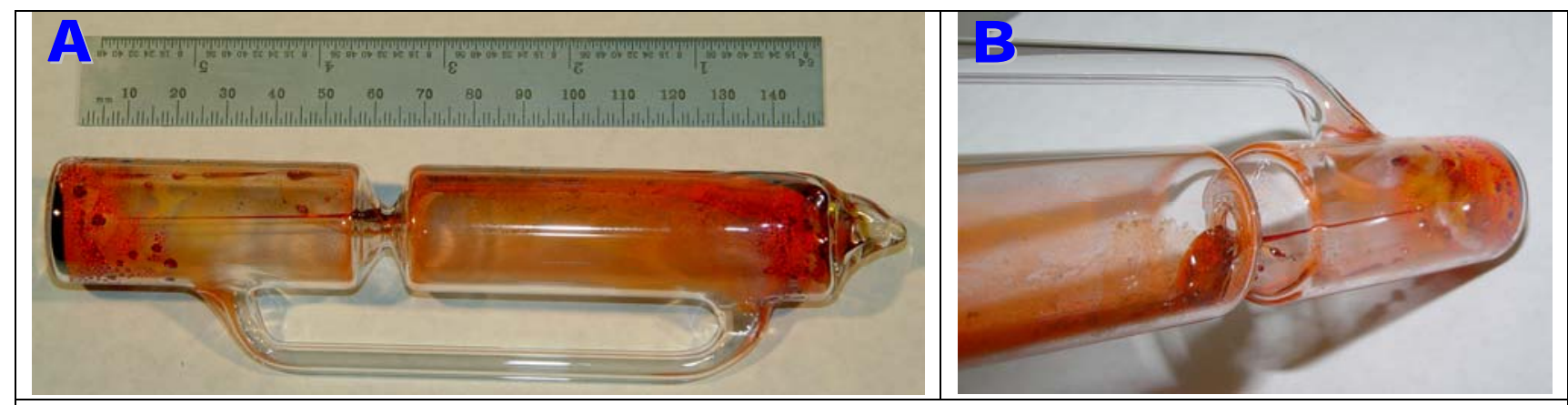

Figure 3.6. The ampoule used for the third experiment set. The bypass tube provided pressure equalization between the two ampoule chambers. 
The ampoule was positioned horizontally within the furnace, with the pressure equalization tube on top to prevent the molten glass from plugging the restriction. The ampoule was taken out of the furnace at around $500^{\circ} \mathrm{C}$ instead of $600^{\circ} \mathrm{C}$. Distinctive droplet formation was observed at $507^{\circ} \mathrm{C}, 500^{\circ} \mathrm{C}, 490^{\circ} \mathrm{C}$, and $488-430^{\circ} \mathrm{C}$. Figure 3.7A shows a droplet forming in the restriction region. Figure 3.7B shows a droplet falling in mid-stream, and Figure 3.7C shows another droplet forming. Based on these experimental observations, at the minimum temperature for As2S3 glass droplet formation was 430 $490^{\circ} \mathrm{C}$.

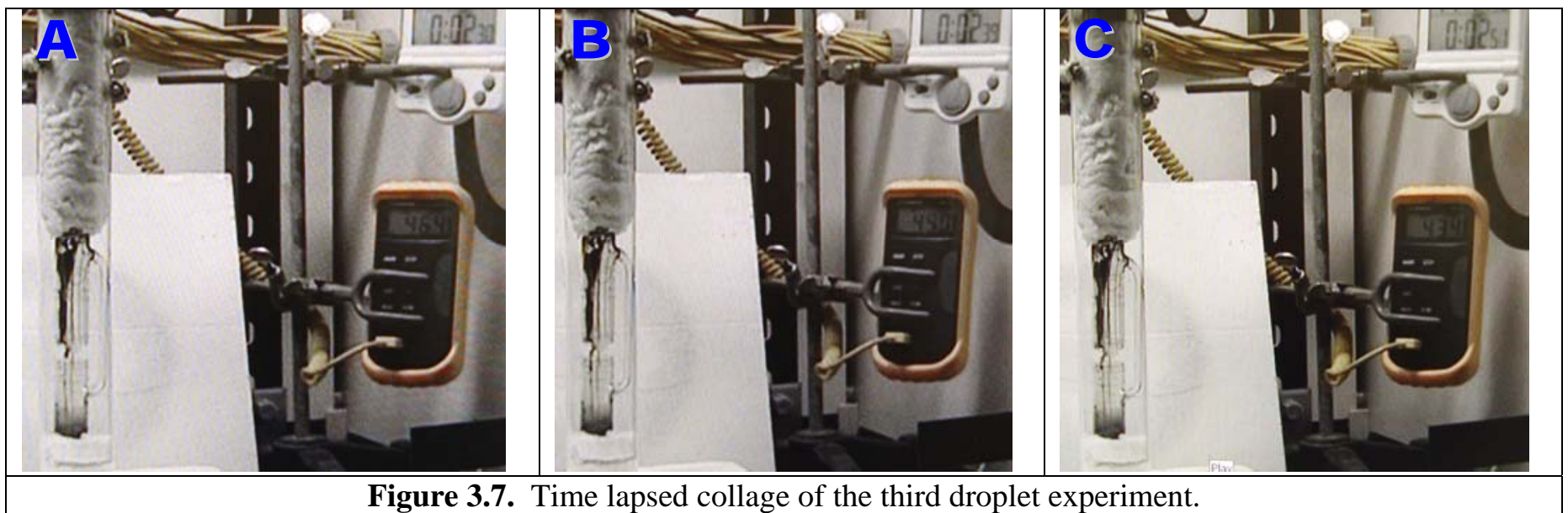





\subsection{Potential Fabrication Techniques}

As a practical realization of the ideal continuous gradient index profile, a step index approximation was proposed for retroreflection applications at $10 \mu \mathrm{m}$. It was shown that to approximate the continuous gradient, a high and low index optical material with good transmission in the LWIR region must be identified, and then their layer thickness must be optimized for best imaging performance. Although a useful step index profile can be obtained using optical modeling, constructing the physical device still presents challenges. Two methods are presented below as examples of potentially feasible methods of fabrication. The first method is based on compression molding. The second method involves sphere fabrication using a unique micro-nozzle approach.

\subsection{Molding Chalcogenide Glass}

Compression molding of optical elements in glass is a proven method of replicating complex aspheric shapes. Corning Glass Works (U.S. Patent No. 4,929,265 1990) and Kodak are two well-known companies in the United States who pioneered this technology, which is now exploited by many offshore manufacturers (mainly Japanese) in products like DVD recorders as well as camera cell phones. The benefits of this technology lie in the ability to share the cost of mold production over many copies, thus reducing the price per element. Aspheric molds are routinely produced using precision single point diamond turning machines in metal molds, or by precision grinding machines using ceramic mold materials. Proprietary RF sputtered coatings are used on the molds as both release agents and wear layers to extend mold life.

An enabling technology that accelerated molded lens technology was the invention low melting point glasses, such as Corning's proprietary C0550 glass. The invention of these low temperature glasses permitted the use of metallic mold technology, which is not possible with more common oxide glasses such as BK7 that have melting points several hundred degrees higher. A typical mold structure consists of a high temperature alloy, such as Inconel 718, as the base into which the net shape of the asphere is machined. Then, the mold is coated with a ductile material, such as electroless nickel, which can be shaped by a single point diamond tool. Electroless nickel can be diamond turned with acceptably low surface roughness, and it is not so hard that it accelerates tool wear markedly. The nickel-surfaced mold is then heat treated to increase its hardness for use in the molding process. If one were to use this nickelsurfaced mold on more common glasses like BK7, it would require the temperature to be raised above the annealing temperature of the heat treated nickel, which would soften it and cause its figure to be distorted in the molding process, reducing mold life (and increasing manufacturing costs). Ceramic molds permit the use of a greater variety of glasses since they maintain their hardness over a much greater temperature range. The use of ceramic molds is somewhat commonplace in Japan, but the cost per mold is much higher, and hence the use of ceramic molds is only cost effective in very high volume production (millions of lenses). Also, the grinding process does not allow certain surface features to be produced in the mold, such as diffractive surfaces for hybrid lenses. Metallic molds are still a viable technology in quick-turn, low- to medium-volume production. 
Chalcogenide glasses have material properties that are very similar to the more common lowtemperature glasses used in aspheric lens molding. For example, a readily available commercial glass, AMTIR3 from Amorphous Materials, has a glass transition temperature of $278^{\circ} \mathrm{C}$, which is very close to that of Corning's $\mathrm{C} 0550$ glass of $330^{\circ} \mathrm{C}$. The glass transition temperature is approximately the temperature at which glass compression molding takes place. Therefore, the extension of already existing molding technology to the chalcogenide glasses is relatively straightforward and can exploit the installed base of molding machinery used for common low-temperature glasses used in lens manufacturing for visible and near-IR applications. One can expect comparable mold life and a similar manufacturing cost per lens, not taking material cost of the glass into account. Glass molding technology can be exploited to produce the structures that are likely needed to make efficient retroreflectors for the MWIR and LWIR sensing applications.

\subsection{Glass Shell Method}

In this approach, one obtains the central core ball lens that is manufactured in the traditional manner of ball lenses by tumbling and polishing. Next two round windows ("preforms") are polished to the final design thickness of the outer shell with the correct outer diameter to ensure sufficient volume is present to form one half of the shell. The outer diameter is slightly over-sized to permit forming in a mold cavity.

Then, each preform is positioned over a spherical mold having dimensions corresponding to the outer spherical shell and made to slump and conform to the shape of the spherical mold by raising the temperature of the glass in an oven as shown in Figure 4.1. Figure 4.2 shows the core ball being inserted into one mold half, while the second mold have is made to travel concentrically with the first mold half. The entire apparatus is then heated until the glass in each mold half reaches the glass transition temperature, $T_{g}$, (the temperature region where the glass begins to soften) and the top mold is made to move against the stationary bottom mold and thus conform to the shape of the core ball lens under the influence of temperature and pressure. The top mold is allowed to travel past the hemispherical seam line while an integral cutting feature in the top mold shears excess glass from the clad structure. The finished product is removed from the mold and used as-is or post polished to eliminate potential scattering from the seam area. 


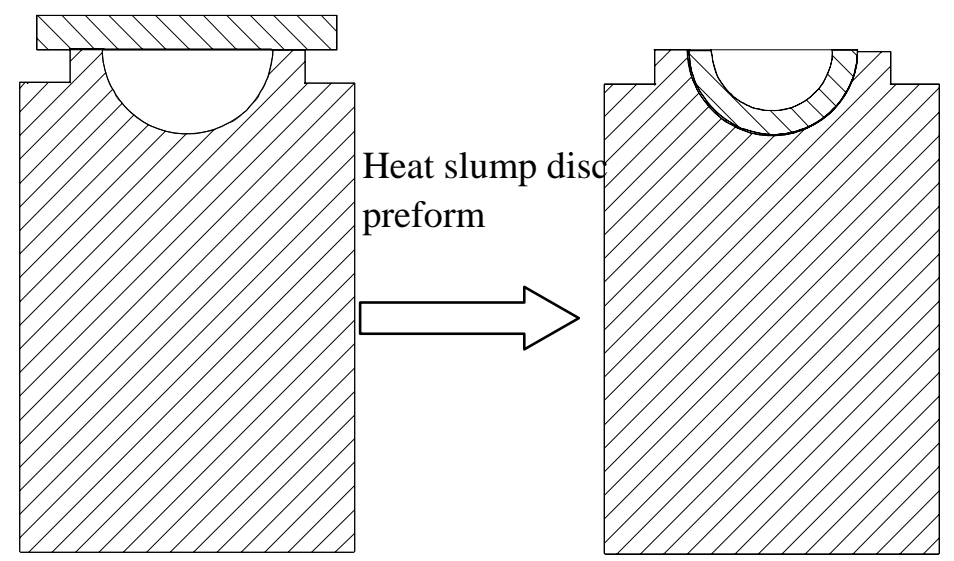

Figure 4.1. Step one in over molding process for outer cladding of the core ball lens. The disc preform is slumped into the spherical mold for both top and bottom molds.

Load ball lens and press
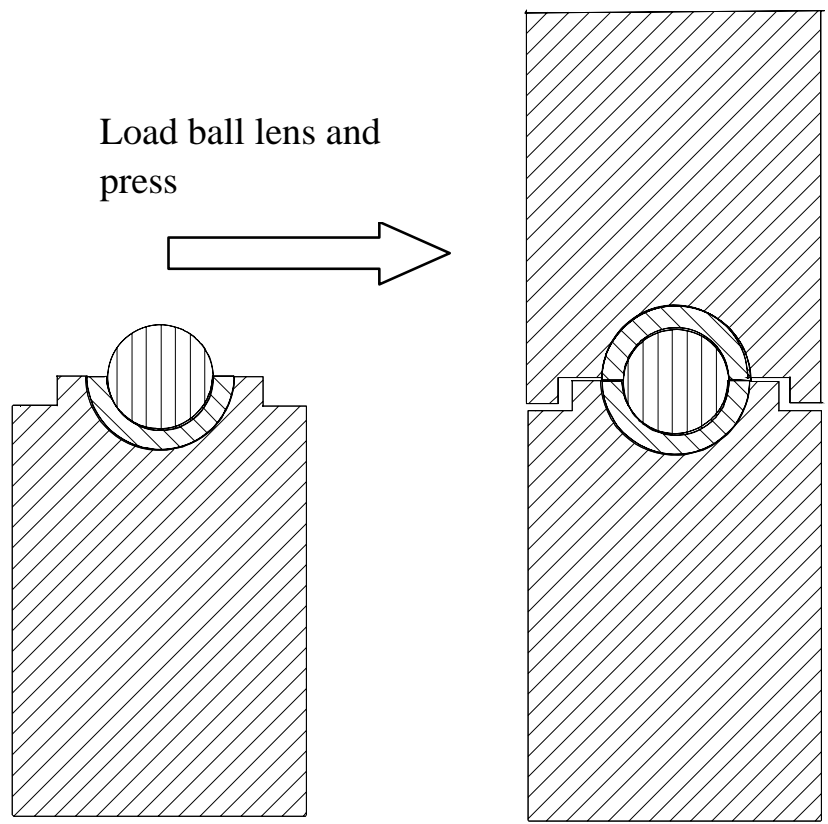

Figure 4.2. Step two involves placing the core ball lens into the bottom slumped mold. The second, or top, mold is inverted and oriented along the axis of the bottom mold. A sleeve (not shown) can be used to ensure coaxial movement between the top and bottom molds. Cutting features can be designed into the molds to shear excess glass.

\subsection{Hot Pressed Method}

This is a variation of the first method in which a hot-pressed high-index IR material is selected with good transmission at $10 \mu \mathrm{m}$, for example, ZnSe. In this approach cladding glass, in powdered form, is pressed around the central glass ball lens under high pressure and temperature. In both cases, the central ball lens must be chosen from a material that will not be affected by the over molding process parameters of temperature and pressure needed for forming the glass of the outer shell. 


\subsection{Flow Focusing Inc. Micro-nozzle Method}

The idea of fabricating extraordinarily uniform diameter microbubbles via a high velocity nozzle originated from Alfonso Ganan-Calvo at the Universidad de Sevilla in Spain (Calvo and Arias 2001). His pioneering work showed that depending on the material and the flow parameters a multiphase liquid can be extruded as either a stable rapid quenched filament (e.g. optical fiber) or be broken into uniform sized droplets. The purpose of PNNL's investigation was to determine if this Flow Focusing Inc. approach could produce homogeneous miniature chalcogenide spheres. Since the Flow Focusing Inc. technique has been used to encapsulate particles, e.g. for drug delivery applications, it is entirely possible that a micronozzle design could also produce clad chalcogenide ball lenses.

To develop miniature sphere fabrication method using the Flow Focusing Inc. micro-nozzle technique, a PNNL fiber optic draw tower was retrofitted with a micro-nozzle assembly as shown in Figure 4.3. The processing begins by heating the glass in a platinum crucible and allowing it to flow through an orifice at the bottom of the crucible. The micro-nozzle injector is centered in the crucible orifice and pressurized with inert gas. A funnel-shaped lens of liquid is produced by the pressure drop across the orifice. By controlling the flow rate of liquid glass and the micro-nozzle pressure, a steady stream of small glass spheres can be produced as shown in Figure 4.4.

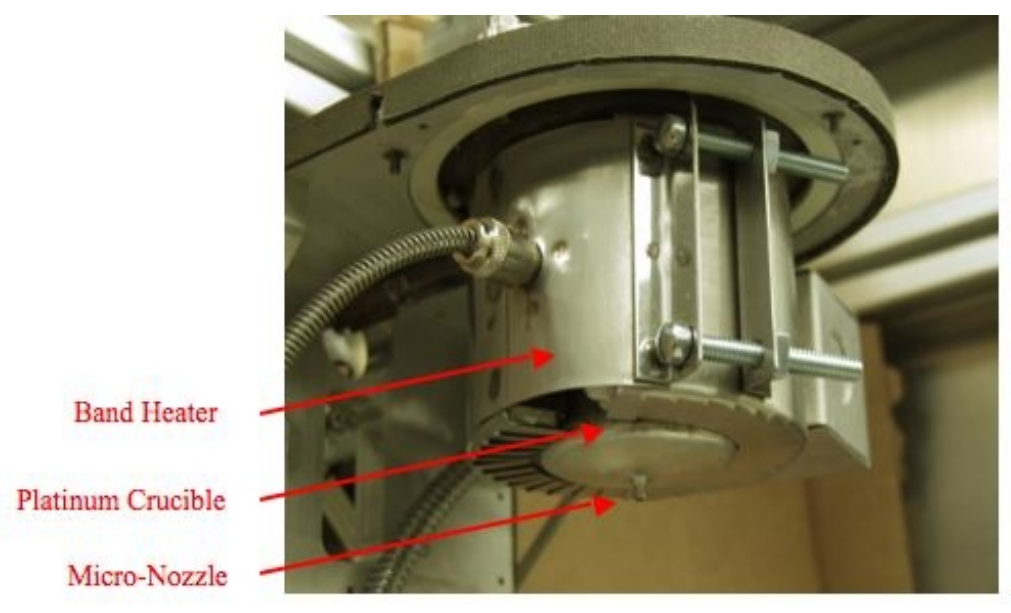

Figure 4.3. The Flow Focusing Inc. assembly installed on the PNNL fiber draw tower. A band heater is used to heat the glass in the platinum crucible. The crucible is double-shelled, where the outer shell forms the micro-nozzle assembly. 


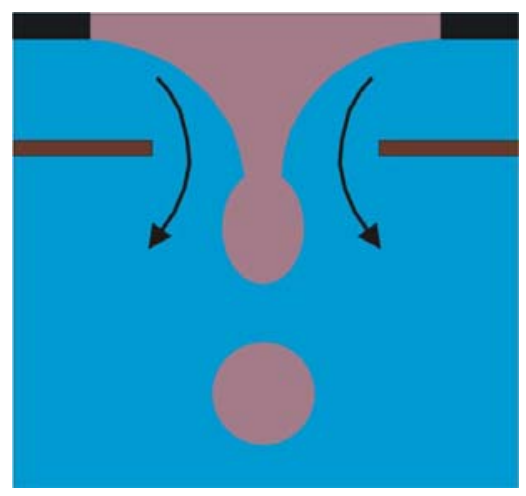

Figure 4.4. The Flow Focusing Inc. technology produces a thin jet of liquid that is pushed through the micro-nozzle aperture. Because the fluid is guided through the aperture by inert gas (arrows), the liquid jet never touches the aperture. The liquid jet then rapidly breaks up into uniform sized droplets (adapted from Calvo's paper).

The draw tower and micro-nozzle experiments were initiated with a nontoxic glass composition that had a glass transition temperature and thermal visco-elastic properties similar to that of chalcogenide glass. The nontoxic glass was used to establish the sphere fabrication methods before using the costly and potentially toxic chalcogenide glass. The micro-nozzle was equipped with a specially designed band heater that provided controlled glass heating up to $700^{\circ} \mathrm{C}$. Initial micro-nozzle experiments demonstrated the ability to shear the viscous glass stream into droplets by judicious control of the glass melt temperature and nozzle flow pressures. While the initial optical quality of the glass spheres was poor, the fabrication approach was verified. It is anticipated that research during FY 2006 will establish the correct combination of glass temperature, micro-nozzle pressure, and optimized orifice and nozzle diameters that will provide uniform optical quality spheres. 



\subsection{Summary}

A model for a symmetrical retro reflector for LWIR applications has been presented that is based upon a ball lens. Homogeneous glass ball lenses, while ubiquitous and inexpensive, cannot return the input beam with good enough efficiency over a large aperture to make them worthwhile candidates for high performance remote sensing systems. However, their use should not be discarded for an application with more modest performance needs.

In an extension to the Luneburg lens model, a spherical gradient index was designed using real-world LWIR material initial index values (for $\mathrm{As}_{2} \mathrm{Se}_{3}$ ) that showed excellent image quality (and hence an efficient energy return). However, the index change of approximately 0.5 is not presently realizable with any known index modulation technique. Alternatively, a two-level step index approximation to the ideal profile was designed using a $\mathrm{ZnS}$ core and $\mathrm{As}_{2} \mathrm{Se}_{3}$ shell that showed marked improvement over the homogenous ball lens reflector.

Three potential methods were suggested for manufacturing these elements, two utilizing variations on compression molding and the third based on a Flow Focusing Inc. micro-nozzle. Chalcogenide glass viscosity measurements have provided the thermal visco-elastic data needed for the micro-nozzle experiments. Initial micro-nozzle experiments demonstrated the ability to shear the viscous glass stream into droplets by judicious control of the glass melt temperature and nozzle flow pressures. While the initial optical quality of the glass spheres was poor, the fabrication approach was verified. It is anticipated that research during FY 2006 will establish the correct combination of glass temperature, micro-nozzle pressure, and optimized orifice and nozzle diameters that will provide uniform optical quality miniature spheres. During FY 2006 PNNL will also develop compression-molding methods and begin evaluating miniature spherical retroreflector performance.

We wish to thank Dr. S.K. Sundaram and Dr. Mary Bliss for providing valuable consulting on glass material properties. 



\subsection{References Cited in the Text}

Anheier NC, PJ Allen, PE Keller, WD Bennett, PM Martin, BR Johnson, SK Sundaram, BJ Riley, JE Martinez, A Qiao, and JF Schultz. 2004. FY 2004 Infrared Photonics Final Report. PNNL-15209, Pacific Northwest National Laboratory, Richland, WA.

Calvo AMG, JMG Arias 2001. "Perfectly Monodisperse Microbubbling By Capillary Flow Focusing." Phys. Rev. Lett. 87. 274501.

Kikuchi K, T Morikawa, J Shimada, and K Sakurai 1981. "Cladded radially inhomogeneous sphere lenses." Appl.Opt. 20, 388.

Koike Y, Y Sumi, and Y Ohtsuka 1986. “Spherical gradient-index sphere lens.” Appl.Opt. 25, 3356.

Koike Y, A Kanemitsu, Y Shioda, E Nihei, and Y Ohtsuka 1994. "Spherical gradient-index polymer lens with low spherical aberration." Appl.Opt. 33, 3394.

Solomin AZ and NG Alexopoulos 1979. "Improvement of the coupling efficiency between LEDs and optical fibers.” Appl.Opt. 18, 2062.

U.S. Patent No. 4,929,265, “Method of Molding Glass Optical Elements,” 1990.

Welford, WT and R Winston 1978. "The Optics of Nonimaging Concentrators: Light and Solar Energy." Academic Press, New York. 



\section{Distribution}

No. of

Copies

\section{OFFSITE}

LTC Ariel Cuadrado

United States DOE

NNSA/NA-22

1000 Independence Ave. SW

Washington, DC 20585

Dr. Rhys M. Williams

United States DOE

NNSA/NA-22

1000 Independence Ave. SW

Washington, DC 20585

Dr. David Berry

United States DOE

NNSA/NA-22

1000 Independence Ave. SW

Washington, DC 20585

Mr. Ralph Hastings

United States DOE

NNSA/NA-22

1000 Independence Ave. SW

Washington, DC 20585

Mr. Eric Sander

United States DOE

NNSA/NA-22

1000 Independence Ave. SW

Washington, DC 20585

Mr. W. Randy Bell

United States DOE

NNSA/NA-22

1000 Independence Ave. SW

Washington, DC 20585
No. of

Copies

Professor Henryk Temkin

Program Manager

DARPA/MTO

3701 N. Fairfax Dr.

Arlington, VA 22203-1714

\section{ONSITE}

\section{Pacific Northwest National Laboratory}

Anheier, NC (4) K5-25

Bernacki, BE K5-25

Bruckner-Lea, C K5-25

Clemmer, RG K8-02

Dudder, GB K8-29

Johnson, BR K6-24

Riley, BJ K6-24

Schultz, JF (10) K5-25

Sharpe, SW K8-88

Sliger, WA P8-20

Information Release Office (7) K1-06 
